\title{
LABOUR UNDERUTILISATION IN NEW ZEALAND
}

\author{
Sophie Flynn and Andrea Fromm
}

\author{
Statistics New Zealand
}

\begin{abstract}
The purpose of this paper is to introduce a preliminary measure of labour underutilisation in New Zealand using data from the Household Labour Force Survey (HLFS). Underutilisation measures add value to the suite of labour market indicators already available from the HLFS. In particular, the underutilisation rate complements the unemployment rate by providing a broader picture of unmet demand for paid employment in New Zealand. The concept of underutilisation and the necessity to measure underutilisation is based on recommendations of an International Labour Organization (ILO) Working Group on Underutilisation made in 2008. The Working Group recommended that '... the statistical community should devote serious efforts to introduce, at a par with unemployment, a supplementary concept which measures the employment problem as experienced by individual workers.' The development of underutilisation measures is also important to mirror changes in increasingly transitional labour markets and to enable analysis and evaluation of these changes.
\end{abstract}

\section{Introduction}

The unemployment rate is the most widely used indicator of labour market performance but has for many years been criticised from both an economic and social perspective. Some of the main criticisms are that the unemployment rate:

- fails to capture labour market downturns in all contexts

- does not fit with common perceptions of 'lack of work'

- is no longer sufficient on its own in increasingly diversifying labour markets to describe all aspects of attachment to the labour market and insufficiency in paid work

- fails to capture the economic hardship experienced by individual workers.

In response to these criticisms, the International Labour Organisation (ILO) undertook work to review unemployment measures and other current indicators of the labour market. As a result of this work, the ILO published the report 'Beyond unemployment: Measurement of other forms of labour underutilisation' in 2008. It concludes that '.. the standard definition of unemployment is essentially sound and the resulting data meaningful. The concept should be maintained and continue to be measured as precisely as possible. But, at the same time, the statistical community should devote serious efforts to introduce, at a par with unemployment, a supplementary concept which measures the employment problem as experienced by individual workers. Thus, the measure should be able to reflect not only total lack of work as measured by unemployment, but also other insufficiencies in the volume of work ...'(ILO 2008). The measures that are being proposed as these supplementary or complementary measures are measures of labour underutilisation.

\section{Who are the underutilised?}

Labour underutilisation reflects the total number of people in the labour force who are not being fully utilised as well as some who are outside of the labour force who can be considered 'potential labour supply'. The measure is concerned with issues of quantity of employment, rather than quality of employment.

The employed, unemployed, and not in the labour force groups are traditionally treated as discrete categories in the conventional labour force framework. If we instead view labour market activity as a continuum (as in figure 1 ), there is a group on either side of unemployment that 

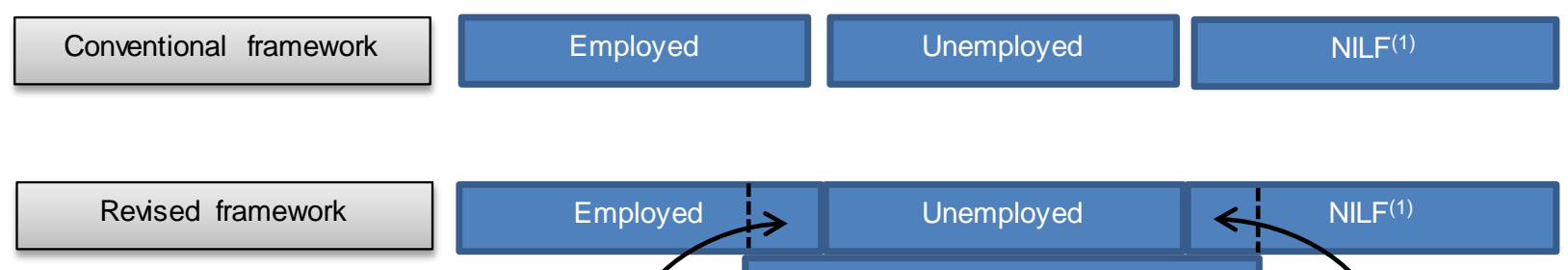

1. Not in the labour force

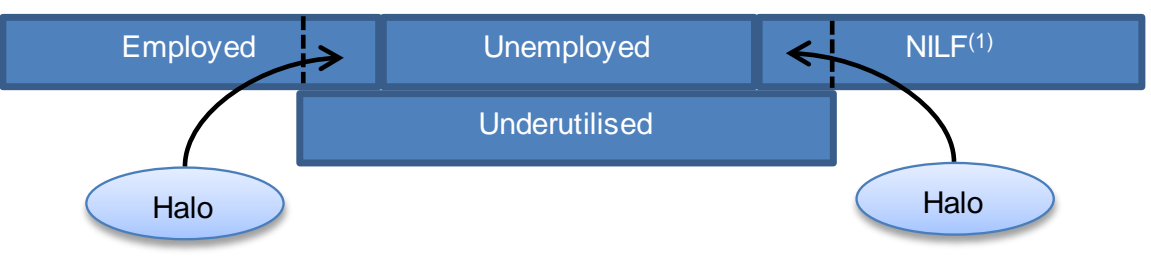

share some characteristics with the unemployed. These two groups are often referred to as the 'halos' of unemployment and together with the unemployed form the population considered to be underutilised. These two halos are the underemployed (on the 'employment' side) and the marginally attached (on the 'not in the labour force' side).

\section{The underemployed (employed halo)}

There are a number of types of underemployment. The measure used here is time-related underemployment which exists when an employed individual wants to work more hours than they usually do and is available to do so.

The international guideline ${ }^{1}$ defines the underemployed as those employed individuals who:

- worked less than a specified threshold of hours (usually part-time), and

- $\quad$ would like to work more hours, and

- were available to do so in the reference week.

\section{The marginally attached (not in the labour force halo)}

The marginally attached are those who are not in the labour force but can be considered to be just outside of it. They meet two of the three criteria needed to be considered unemployed. There are two main groups of marginally attached individuals:

- those who are actively seeking work but who were not available to have started work in the reference week,

- those who are not actively seeking work but were available in the reference week (the 'discouraged' are included in this group).

The first group is considered to have slightly closer attachment to the labour market than the second group, but both groups have much stronger attachment than other groups who are not in the labour force. There is some variation across countries in which sub-groups of these two larger groups are considered to be marginally attached.

\section{Current international practice}

Many countries are already releasing data on the number of underutilised, the sub-groups of underutilisation, and the associated rates.

In 2010, Eurostat started releasing three new indicators to supplement the unemployment rate. These were the parttime underemployed, persons seeking work but not available, and persons available for work but not seeking it. The numbers showed that in 2011, in addition to the 23.0 million unemployed people in the EU-27, there were 8.6 million underemployed workers, 2.4 million persons seeking work but not available, and 8.6 million persons available for but not seeking work, making the underutilised population almost double that of the unemployed alone (Eurostat 2012).

The U.S. Bureau of Labor Statistics also releases measures of underutilisation with a suite of indicators released together ranging from long-term unemployment, to the total underutilisation rate. This showed that in 2011 the unemployment rate was 8.9 percent, while the underutilisation rate was 15.9 percent (U.S. Bureau of Labor Statistics 2012).

Figure 2 compares selected countries on three of the U.S. Bureau of Labor Statistics' six underutilisation measures. Comparing the New Zealand and Australian data provides a useful example of the different measures as they show while the traditional unemployment rate was higher for New Zealand, both the long-term unemployment (defined as 15 weeks or longer here) and total underutilisation rates as higher for Australia. 


\section{Figure 2}

\section{Various measures of labor underutilization, selected countries, 2009}

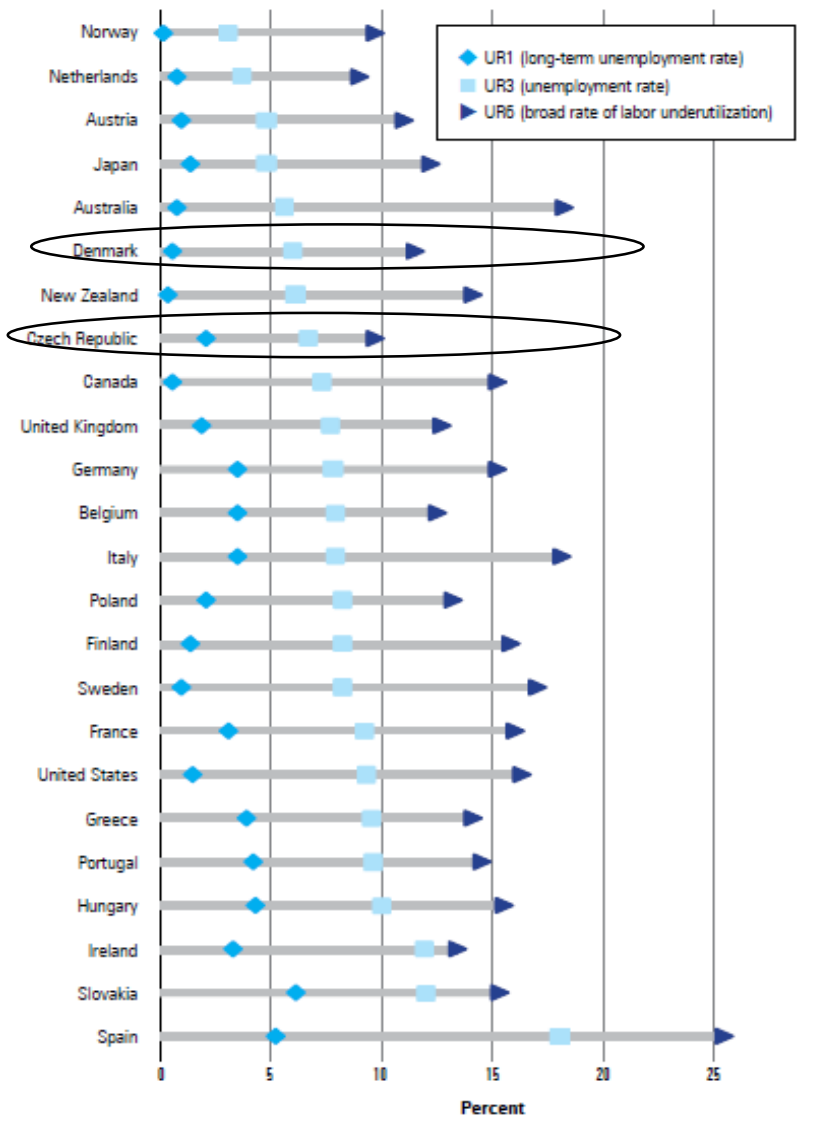

NOTE: Long tem is defined as 1 year or longer. UR6 includes the unemployed, the marginally attached, and the timerelated underemployed. See section notes

SOURCES: Bureau of Labor Statistics and Organisation for Economic Co-operation and Development

While there is now a fairly commonly understood definition of who should be counted as underutilised, one area that remains problematic in terms of gaining consensus internationally is the denominator for calculating rates for each of the separate measures and for the overall underutilisation rate. The denominators being discussed are the labour force, an extended labour force (the labour force plus the marginally attached), and the working-age population (WAP). Different countries have adopted different practices and while this affects international comparability, measures can be calculated on the same basis to promote comparability when necessary. The current ILO proposals offer countries the choice of which denominator to use.

\section{The provisional New Zealand measures}

The HLFS provides the data needed to calculate measures of the underemployed, the unemployed, the marginally attached, and the total underutilised population back to the March 2004 quarter. The definitions used for the measures in this paper follow.

\section{The underemployed}

The HLFS introduced new survey questions in the March 2004 quarter to enable the official measurement of underemployment.
The underemployed are those who:

- $\quad$ are employed part-time (usually work less than 30 hours per week), and

- would like to work more hours than they usually do, and

- were available to do so in the reference week.

The underemployment rate (UER) is calculated as:

Number of underemployed persons

Labour force

x100

\section{The unemployed}

The unemployed are those who:

- were not employed in the reference week, and

- were actively seeking work in the four weeks prior to the reference week or had a job to start in the next four weeks, and

- $\quad$ were available to start work in the reference week.

The unemployment rate (UR) is calculated as:

$\frac{\text { Number of unemployed persons }}{\text { Labour force }}$ x100

\section{The marginally attached}

The marginally attached are those who were:

- actively seeking work in the four weeks prior to the reference week (or had a job to start in the next four weeks), but who were not available to have started work in the reference week, or

- available to start work in the reference week but who were not actively seeking work in the four weeks prior to the reference week and did not have a job to start in the next four weeks.

The marginal attachment ratio (MAR) is calculated as:

$$
\frac{\text { Number of marginally attached persons }}{\text { Labour force }}
$$

Note that this is a 'ratio' as it is relative to the size of the labour force, but not part of it.

\section{The underutilised}

The underutilised are those who are:

- underemployed, or

- unemployed, or

- marginally attached.

The underutilisation rate (UUR) is calculated as:

$$
\frac{\text { Number of underutilised persons }}{\text { Working-age population }}
$$


For the underutilisation rate, the WAP has been chosen as the denominator as it provides the total picture relevant to the population and makes interpretation clear and simple.

\section{The data}

The results reported in this paper use unadjusted survey data and compare June quarters only to account for any seasonal effects in the data.
Just over a tenth of the New Zealand WAP was underutilised in the June 2012 quarter. This compares with the June 2006 quarter where the underutilisation rate was at a low of 6.1 percent. The number of people who were underutilised in June 2012 was 2.4 times higher than the number of unemployed alone.

Table 1: Underutilisation, June quarters, unadjusted data

\begin{tabular}{|c|c|c|c|c|c|c|c|c|}
\hline \multirow[b]{2}{*}{ Quarter } & Underemployed & Unemployed & $\begin{array}{l}\text { Marginally } \\
\text { attached }\end{array}$ & Underutilised & $\begin{array}{l}\text { Underemployment } \\
\text { rate }\end{array}$ & $\begin{array}{l}\text { Unemployment } \\
\text { rate }\end{array}$ & $\begin{array}{c}\text { Marginal } \\
\text { attachment ratio }\end{array}$ & $\begin{array}{c}\text { Underutilisation } \\
\text { rate }\end{array}$ \\
\hline & \multicolumn{4}{|c|}{$(000)$} & \multicolumn{4}{|c|}{$(\%)$} \\
\hline June 04 & 63.3 & 84.7 & 68.4 & 216.4 & 3.0 & 4.1 & 3.3 & 6.9 \\
\hline June 05 & 64.2 & 79.5 & 67.8 & 211.6 & 3.0 & 3.7 & 3.2 & 6.6 \\
\hline June 06 & 55.8 & 79.2 & 63.4 & 198.3 & 2.5 & 3.6 & 2.9 & 6.1 \\
\hline June 07 & 69.2 & 79.9 & 81.8 & 230.9 & 3.1 & 3.6 & 3.6 & 7.0 \\
\hline June 08 & 68.0 & 87.5 & 83.0 & 238.5 & 3.0 & 3.9 & 3.7 & 7.2 \\
\hline June 09 & 95.7 & 133.5 & 102.7 & 331.8 & 4.2 & 5.8 & 4.5 & 9.8 \\
\hline June 10 & 87.2 & 155.3 & 100.4 & 342.8 & 3.8 & 6.7 & 4.3 & 10.0 \\
\hline June 11 & 96.4 & 149.9 & 101.2 & 347.4 & 4.1 & 6.4 & 4.3 & 10.0 \\
\hline June 12 & 96.4 & 156.4 & 114.8 & 367.6 & 4.1 & 6.6 & 4.8 & 10.5 \\
\hline
\end{tabular}

Source: Statistics New Zealand

\section{Figure 3}

\section{June quarter changes relative to the June 2004 quarter}

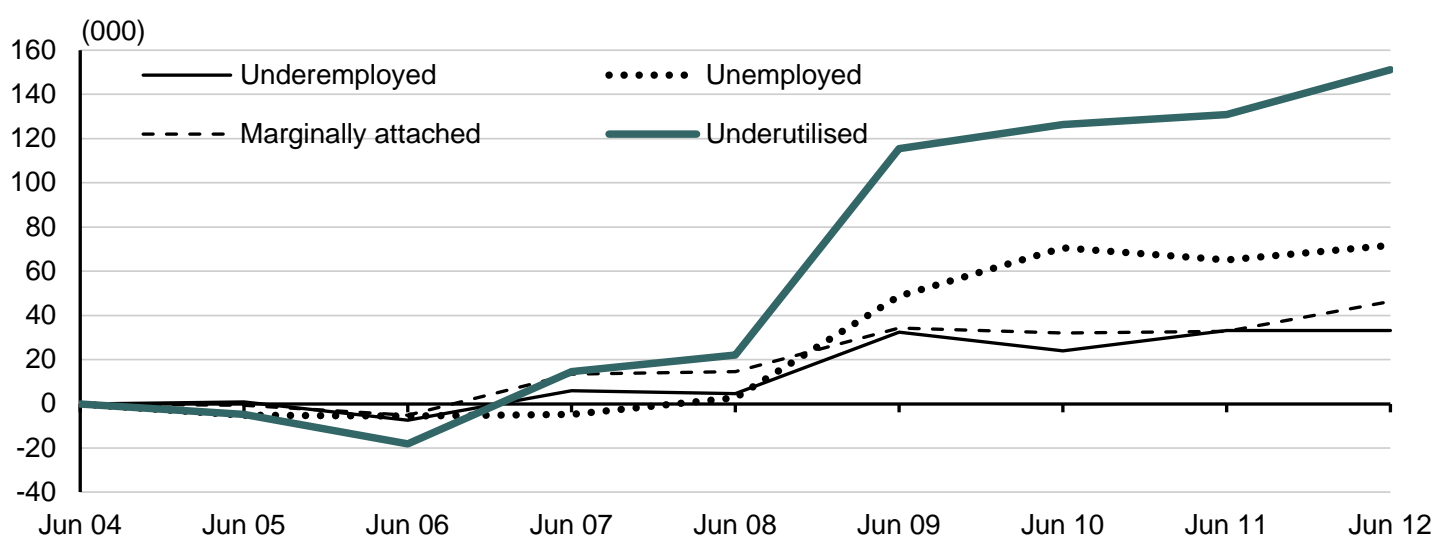

Source: Statistics New Zealand

Table 1 shows how the underemployment rate, marginal attachment ratio, and underutilisation rate all recorded an annual increase in the June 2007 year, while the unemployment rate was flat over this period. The unemployment rate then starts to increase by the following year.

Figure 3 shows that the June 2009 quarter recorded the largest annual increases across all of the measures. Underemployment increased by 40.8 percent, unemployment grew by 52.6 percent, marginal attachment rose by 23.7 percent, and the overall number of underutilised increased by 39.2 percent to 331,800 people. In the June 2009 quarter, the number of underutilised people was two-and-a-half-times higher than the unemployed alone, and the underutilisation rate was 4.0 percentage points higher than the unemployment rate.

Sex

Since the June 2004 quarter, the female underutilisation rate has on average been 1.6 percentage points higher than the male underutilisation rate. This compares to the 
difference in the unemployment rate which has been an average of 0.5 percentage points in June quarters since 2004. Figure 4 shows that while the number of men and women who are unemployed is fairly similar, women are more strongly represented in the underemployed and the marginally attached populations than men.

The distributions seen in figure 4 are fairly illustrative of the June quarter series. However, there were some small shifts in the male/female distribution in the June 2008 to June 2011 quarters.

\section{Figure 4}

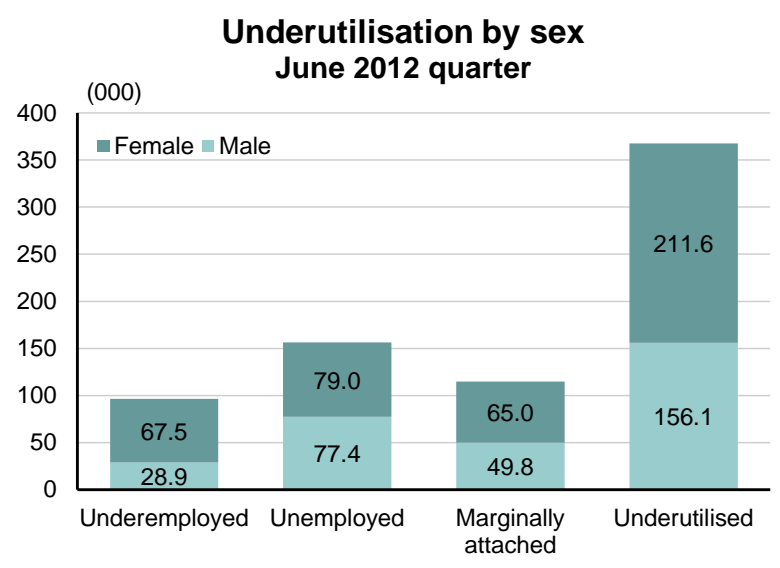

Source: Statistics New Zealand

The number of women who are underemployed is particularly significant, with women accounting for 70.0 percent of the underemployed in the June 2012 quarter (similar to the overall proportion of part-time workers who are women). The underemployment rate for women in the June 2012 quarter was 6.0 percent, while the male rate was 2.3 percent. It is interesting to note that if underemployment numbers are looked at relative to the total number of part-time employed, then we see that 20.6 percent of men employed part-time were underemployed, while 17.7 percent of all women employed part-time were underemployed.

Of all women who were underemployed in the June 2012 quarter, 17.9 percent were employed in the health care and social assistance industry group, 15.0 percent in the retail trade industry, and 13.7 percent in education and training. For underemployed men, 13.6 percent were employed in the retail trade industry and 10.6 percent in the construction industry. These percentages closely mirrored the distribution of part-time work across industry groups with the exception of construction where the male underemployment percentage was greater than the proportion of male part-time employment accounted for by this industry group.

Marginal attachment is also higher in numbers for women than for men. The majority of the difference in this group was in the number of women who were available for work, but not actively seeking. Of these women, 8.8 percent had passively looked for work (looked at job advertisements only), 21.8 percent were not seeking because they were currently in education, and 15.6 percent were not seeking because they were unable to find suitable childcare. This compares to men where 6.6 percent had passively looked for work, 28.2 percent were not seeking work because they were currently in education, and 13.6 percent were not seeking work due to illness or injury.

The number of men and women who were actively seeking, but not available is much more even, although there still tends to be slightly more women in this group than men. Again, women recorded a stronger response of not being available due to personal or family responsibilities than men, 42.7 percent compared to 17.7 percent.

\section{Age group}

In general, both the number of people underutilised and the underutilisation rate decreases as age increases (see figure 5). The youth age groups (15-19-years-old and 20 24-years-old), have both the highest numbers and rates of underemployment, unemployment, marginal attachment, and underutilisation. Just under a quarter of all 15-19year-olds were underutilised in June 2012. Of those underutilised 15-19-year-olds, 70.8 percent were in education in the June 2012 quarter. This compares with only 37.7 percent of underutilised 20-24-year-olds in education. 


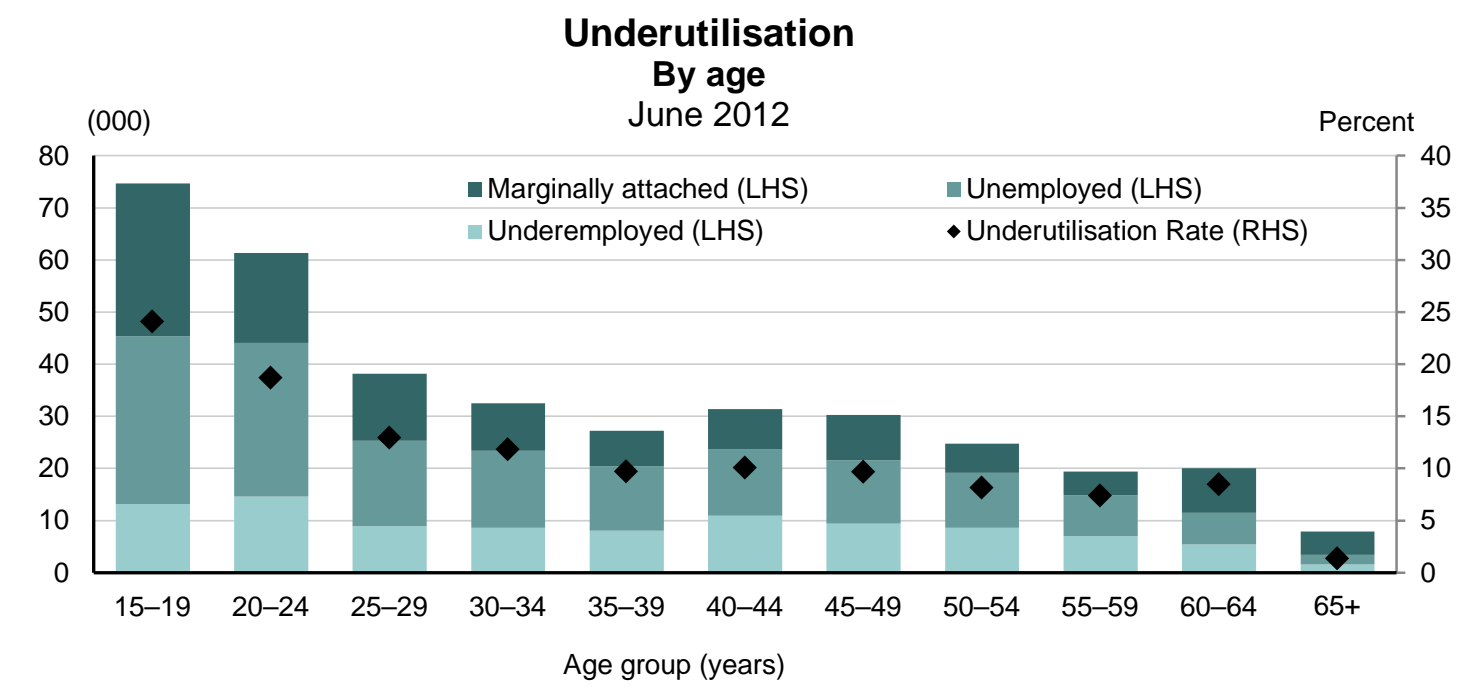

Source: Statistics New Zealand

Figure 6

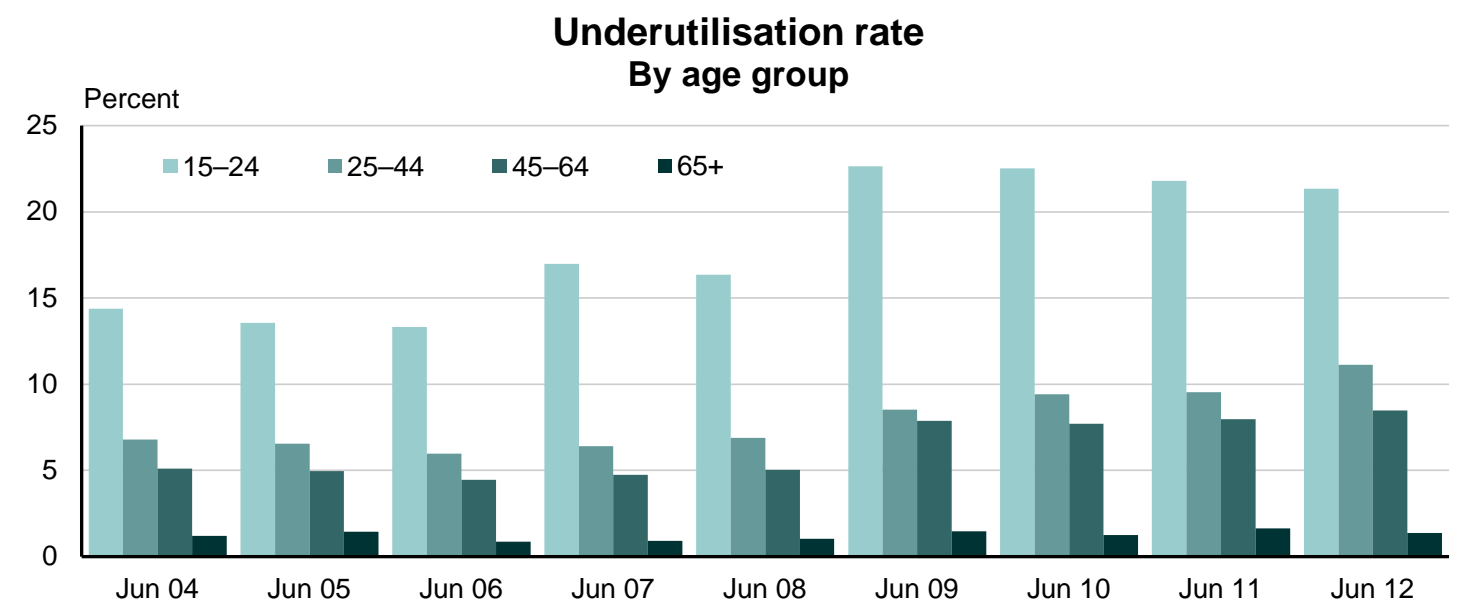

Source: Statistics New Zealand

Figure 6 shows how the underutilisation rates have increased over time for combined age groupings. It clearly shows the difference in magnitude of the underutilisation rate for the 15-24-year-old group when compared to other groups. However, it also appears that the rate for this group has been levelling off and even showing signs of starting to decrease over recent June quarters. In contrast, the 25-44-year-old group and the 45-64-year-old group have both shown steady increases since the June 2008 quarter and both hit a June quarter series high in June 2012.

\section{Ethnicity and country of birth}

Changes were made to the HLFS ethnicity and country of birth questions in the December 2007 quarter, therefore data are available for comparison from this point. Data used in this report utilise the 'total response' method of classifying ethnicity which counts each person in each ethnic group they identify with.
Figure 7

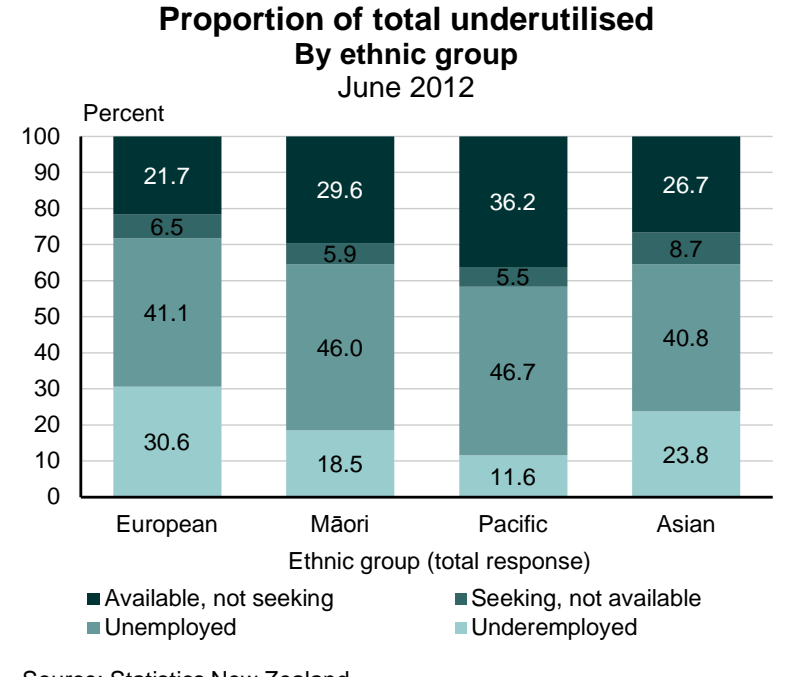

Source: Statistics New Zealand 
Figure 7 shows what proportion of underutilisation is accounted for by each of the separate components for each ethnic group in June 2012. We can see that for all of the ethnic groups looked at, unemployment is the most significant component, although this is more so for Māori and Pacific peoples. Compared with the other ethnic groups, Pacific peoples had notably more of their underutilised coming from the marginally attached groups, and significantly less coming from the underemployment component. For the Māori, Pacific peoples, and Asian ethnic groups, the proportion who are 'available, not seeking' is more significant than the underemployed. This is the opposite for the European ethnic group. For all groups, the percentage who are 'seeking, not available' is the smallest.

Figure 8 shows how each of the individual rate measures compare between ethnic groups over the last five June quarters. Unemployment rates and marginal attachment ratios have in general been highest for the Pacific peoples ethnic group (when compared with the other three groups looked at). In contrast, with the exception of the June 2011 quarter, underemployment rates are relatively low for Pacific peoples, and were the lowest of the four groups for 3 of the 5 quarters. Māori had the highest underemployment rate, as well as unemployment rates and marginal attachment ratios close to those of Pacific peoples across the five June quarters. In the June 2012 quarter, just under a fifth of all Māori and Pacific peoples were underutilised.

The difference in unemployment rates and underutilisation rates between ethnic groups has also increased across the five June quarters looked at. In June 2008 there was a 4.2 percentage point difference between the lowest unemployment rate and the highest, by June 2012 this difference had increased to 9.7 percentage points. The underutilisation rate showed a similar divergence with a 6.0 percentage point difference in June 2008 , increasing to a 10.3 percentage point difference in June 2012.

To acknowledge the different age structures of the ethnic groups looked at, underutilisation rates were looked at by ethnic group for the 15-24-year-old, 25-44-year-old, and 45-64-year-old age groups. Overall the story seen in figure 8 was the same regardless of the age group examined.

Those who were not born in New Zealand and have been living in New Zealand for 10 years or less have higher rates of underemployment, unemployment, and underutilisation than those who were born in New Zealand. Interestingly, those who were not born in New Zealand but who have been here for 11 years or more have rates of underemployment, unemployment and underutilisation even lower than those born in New Zealand.
Figure 8: Underutilisation measures by ethnic group

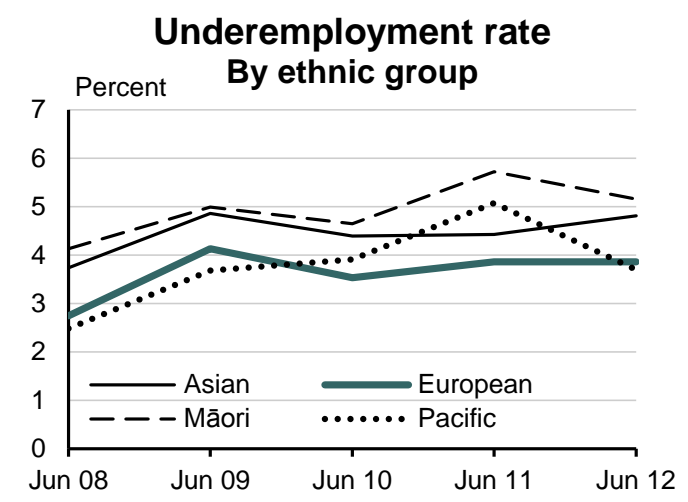

Source: Statistics New Zealand

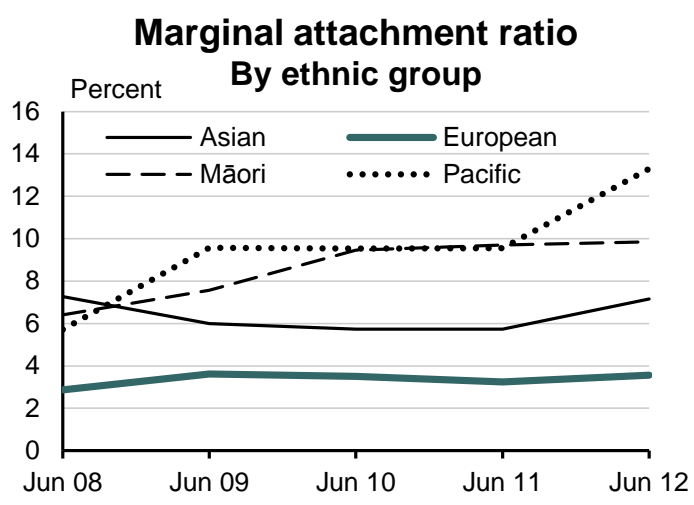

Source: Statistics New Zealand

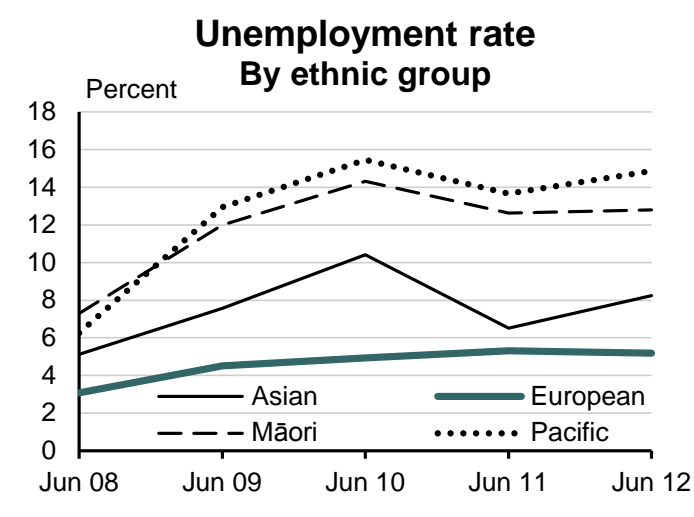

Source: Statistics New Zealand

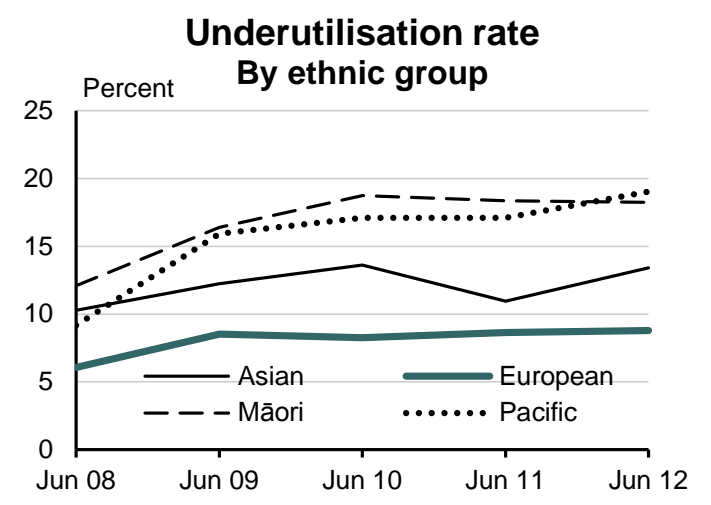

Source: Statistics New Zealand 


\section{Region}

\section{Figure 9}

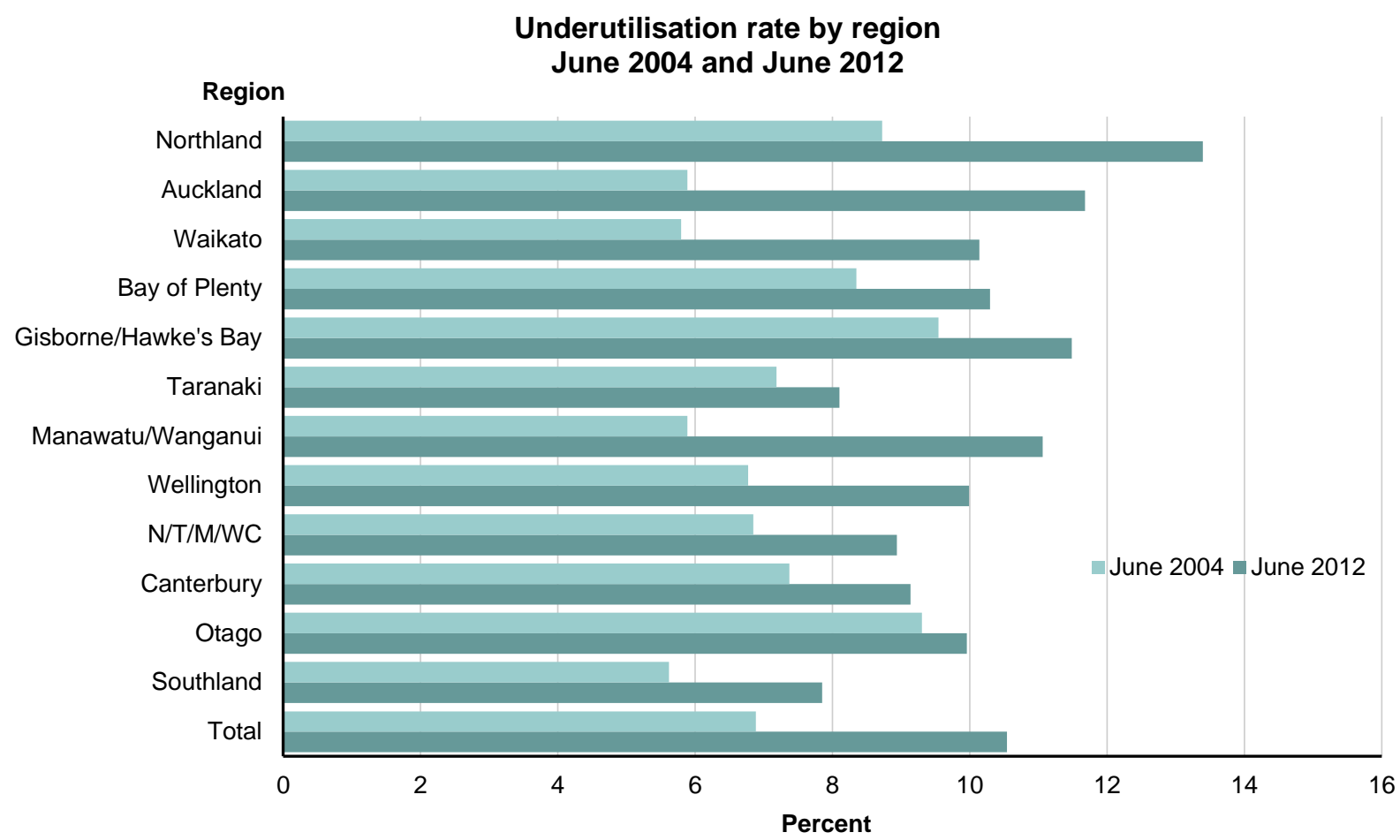

N/T/M/WC = Nelson/ Tasman/ Marlborough/ West Coast

Source: Statistics New Zealand

Figure 9 shows the underutilisation rates by region for the two periods June 2004 quarter and June 2012 quarter. In June 2004, the Gisborne/Hawke's Bay region had the highest underutilisation rate at 9.5 percent. By June 2012, however, the Northland region had recorded an increase of 4.7 percentage points since June 2004 and had the highest rate (13.4 percent). The Northland region also had the highest underemployment rate, unemployment rate, marginal attachment ratio, and lowest employment rate in June 2012. The Southland region had the lowest underutilisation rate in both periods.

The Auckland region recorded the largest increase in the underutilisation rate between June 2004 and June 2012, and went from having the fourth-lowest rate in June 2004 to having the second-highest rate in June 2012. Increases in the Auckland region between these two periods were in all of the subgroups of underutilisation. The number of unemployed increased by 30,900, the number of marginally attached grew by 25,000, and the number of underemployed rose 18,800 between June 2004 and June 2012. Increases to the underutilisation rate were similar to Auckland in the Manawatu/Wanganui region.

\section{Highest qualification}

As expected, those with tertiary or post-secondary school qualifications have lower rates of underutilisation than those with secondary school or no qualifications. Figure 10 shows the unemployment rate for individuals by different level of highest qualification, then figure 11 shows the underutilisation rate for the same groups. What can be seen here is that those with no qualifications have a clearly higher rate of unemployment than those in other qualification groups. This distinction is not the same when we look at underutilisation rates however, where from the June 2009 quarter those with a school qualification as their highest qualification had the highest underutilisation rate.

\section{Figure 10}

\section{Unemployment rate By highest qualification}

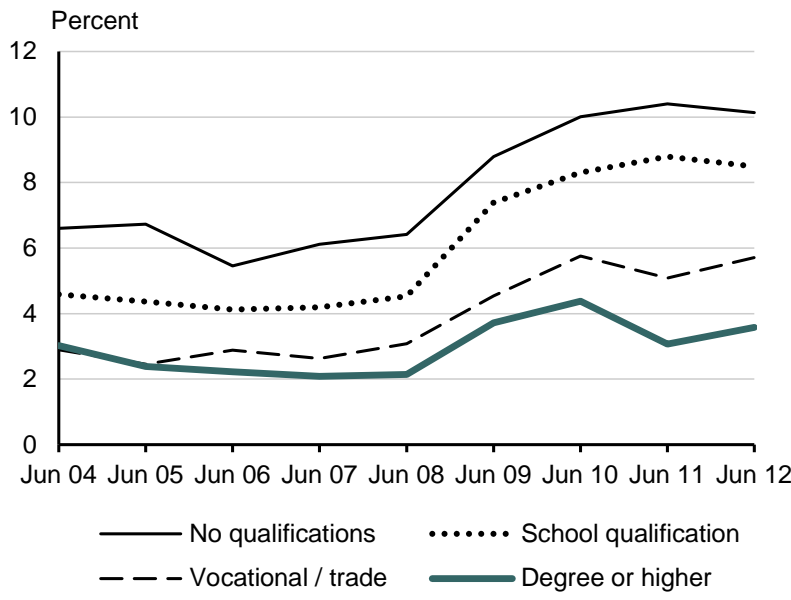

Source: Statistics New Zealand 


\section{Figure 11}

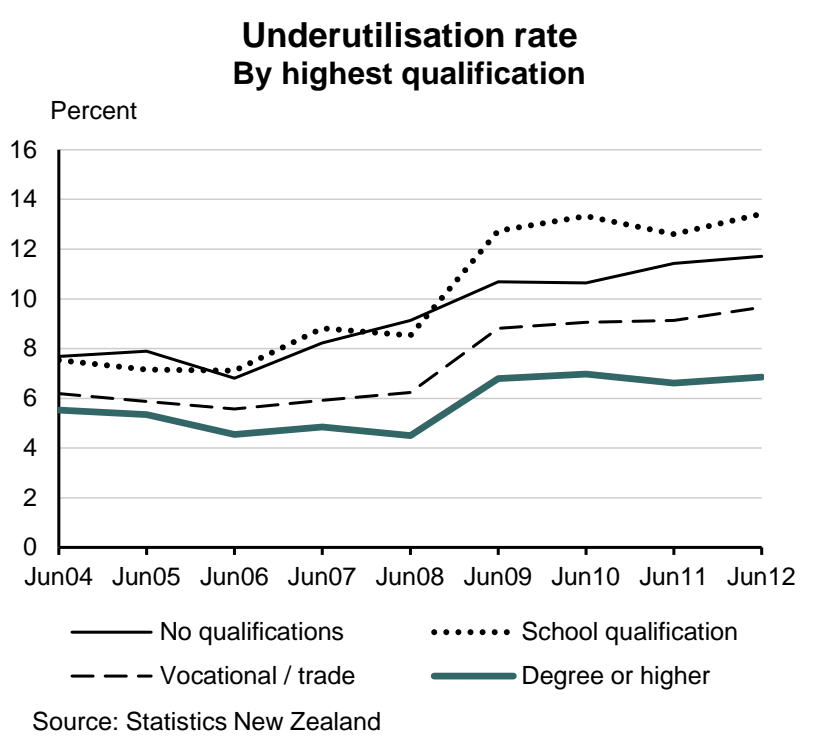

This is largely due to the fact that just under half of those with no qualification are not in the labour force and not marginally attached and that this group also has a low employment rate. Those with a school qualification have a higher employment rate and have experienced a bigger increase in underemployment in the June quarters from 2009 onwards. This illustrates how looking at wider measures of underutilisation, as well as the difference between measures that are relative to the labour force or to the WAP, can provide a different picture of the labour market.

\section{Transitions}

The following analysis compares only those individuals who were in both the June 2011 and June 2012 quarters of the HLFS. Individuals have been classified into one of five groups in each of the quarters and then compared across the two time periods to look at changes. Note that this is a subset only of the complete quarterly HLFS data and as such is more experimental in nature than the official HLFS series.

\section{Figure 12}

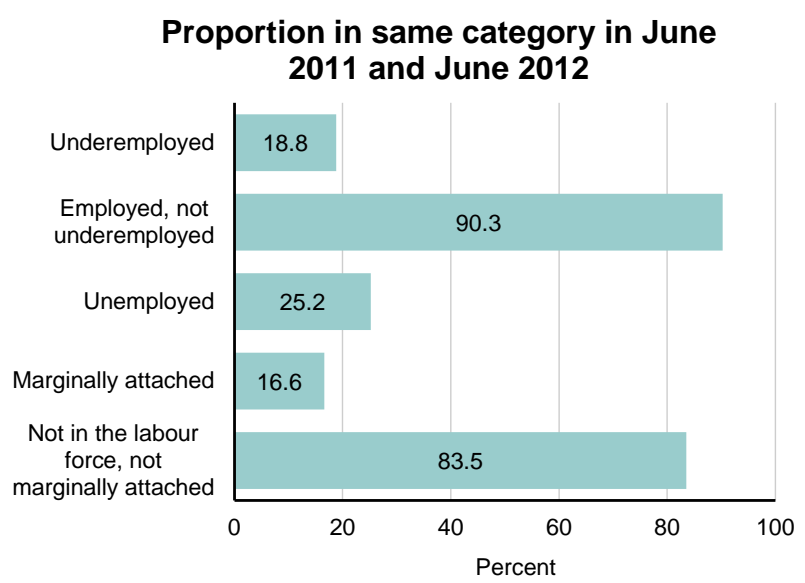

Source: Statistics New Zealand
Figure 12 shows the percentage of those who remained in the same category in June 2012 compared with June 2011. For example, 90.3 percent of those who were 'employed, not underemployed' in the June 2011 quarter were also 'employed, not underemployed' in the June 2012 quarter. This graph clearly illustrates the difference between those 'not in the labour force' that have been identified as marginally attached, and those who were 'not in the labour force' but not marginally attached.

The following graphs look at some of the groups in more detail.

\section{Figure 13}

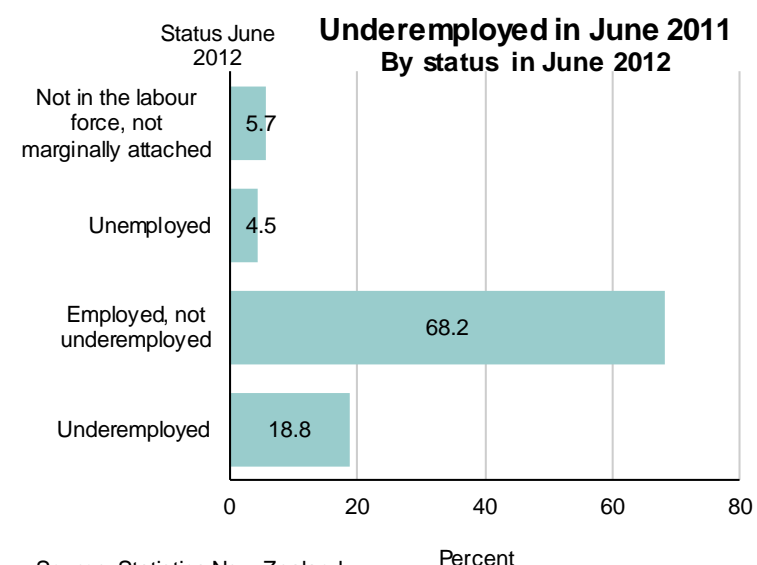

Source: Statistics New Zealand

Percent

Note: the number of people w ho w ere underemployed in June 2011 and marginally attached in June 2012 has been suppressed due to small sample size.

Figure 13 shows those who were underemployed in the June 2011 quarter by their labour market grouping in the June 2012 quarter. Just under a fifth (18.8 percent) were underemployed in both quarters. The majority (68.2 percent) were 'employed, not underemployed' in the June 2012 quarter. Of these, 44.2 percent were in full-time employment and the remaining 55.8 percent were parttime employed but no longer underemployed.

\section{Figure 14}

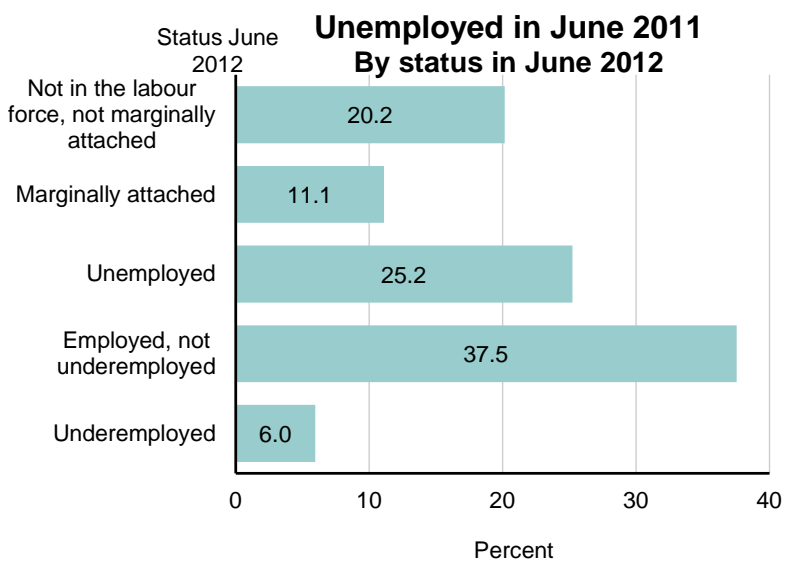

Source: Statistics New Zealand

Of those who were unemployed in June 2011, the largest proportion (37.5 percent) were 'employed, not underemployed' in June 2012. A further quarter were unemployed in both quarters, although it is important to note that this does not mean that they had been 
unemployed during the whole year. Just under a third of those who were unemployed in June 2011 were no longer in the labour force in June 2012.

\section{Figure 15}

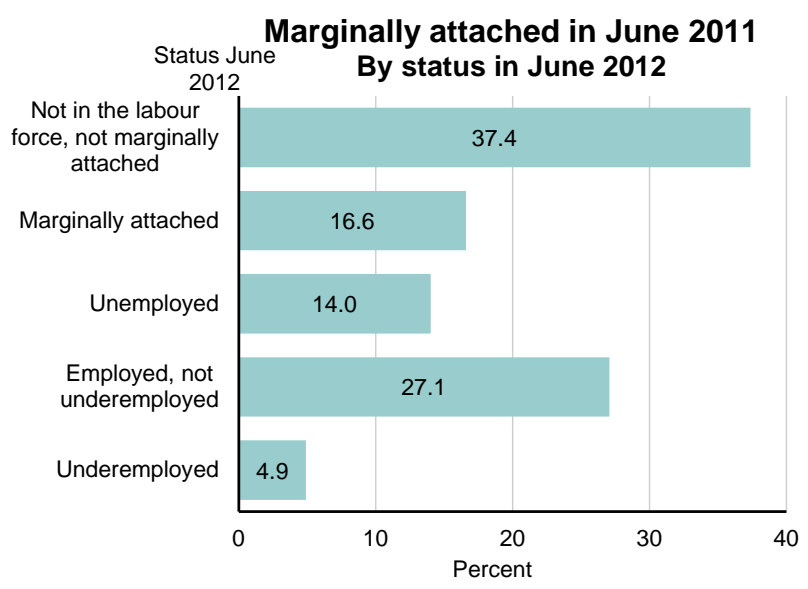

Source: Statistics New Zealand

Just under half of those who were marginally attached in the June 2011 quarter were part of the labour force in the June 2012 quarter, with the largest movement into the labour force going into employment. This compares to only 12.5 percent of those who were 'not in the labour force, not marginally attached' moving into the labour force in the same period. This gives strength to the position that those who have been identified as marginally attached have a closer attachment to the labour force than others who are not in the labour force.

Looking at the marginally attached group further broken down shows that 60.0 percent of those who were seeking but not available in June 2011 were employed in June 2012, while 27.0 percent of those available but not seeking in June 2011were employed in June 2012.

Over a third of the marginally attached moved into the not in the labour force, not marginally attached group. Of these 30.7 percent reported their main activity in June 2012 as studying. A further quarter stated they were at home looking after children, and 23.0 percent said they were retired.

\section{Conclusion}

Underutilisation measures provide a fuller picture of the state of the labour market than the current suite of key indicators currently do on their own. They provide a broader measure of unmet demand for paid employment than the unemployment rate does alone and they enhance the ability to understand increasingly dynamic and changing labour markets.

This paper introduces some preliminary measures of labour underutilisation in New Zealand using data from the Household Labour Force Survey. Following on from this, some further analysis and exploration of the data is needed to further understand the measures, and to move towards producing a regular series to be released alongside other measures from the HLFS.

\section{Notes}

1. Resolution concerning the measurement of underemployment and inadequate employment situations, adopted by the Sixteenth International Conference of Labour Statisticians (October 1998)

\section{References}

Eurostat (2012). European Union Labour Force Survey Annual results 2011. Available from http://epp.eurostat.ec.europa.eu

Eurostat (2012). Labour Force Survey in 2011: Around 8.5 million part-time workers in the EU27 wished to work more hours. Available from http://epp.eurostat.ec.europa.eu

ILO Working Group on Labour Underutilization (2008). Beyond Unemployment: Measurement of Other Forms of Labour Underutilization, ILO: Geneva

U.S. Bureau of Labor Statistics (2012). Alternative Measures of Labor Underutilization for States, 2011. Available from www.bls.gov 